\title{
Observation and Effect of Project Approach: Focused on Film Project
}

\author{
Kyung-chul, $\mathrm{Kim}^{1}$ and Eun ok, Kim ${ }^{* 2}$ \\ ${ }^{1}$ Professor, Department of Early Childhood Education, Korea National \\ University of Education \\ ${ }^{2}$ Doctor's course, Department of Early Childhood Education, Korea National \\ University of Education \\ ${ }^{1}$ kbrian@knue.ac.kr, ${ }^{2}$ ihope1201@hanmail.net
}

\begin{abstract}
Humans have a desire for creation. Since humans started using tools, we have made various tools and instruments for easier life. We feel delighted and alive when creating or producing new things. The activities related to creation can be realized through creative expressions using language, arts, and body, or expression of thoughts in discussion. Movie is one of the diverse approaches for this. Movie is very complex composite art, and movie making requires a large pool of expert professionals. For this reason, an experience of movie making for children and examination into the process of changes observed in them will hold great significance. The study subjects were 5-year-old children of class 1 at B kindergarten located in K city. The study was conducted for 4 weeks of December, 2015. Data were collected through photographs of children from the activities and recordings of interactions which took place during the activities of motion pictures and movie making. The recordings were transcribed for analysis. One co-teacher, one professor, and one expert reviewed and analyzed them. The study results were: first, the children actively participated in the creative and productive process of movie making. Second, they performed diverse roles to host a movie screening.
\end{abstract}

Keywords: Early childhood Education, Movie, project approach

\section{Introduction: Children in Local Communities}

Humans have an innate desire to create. Since mankind began using tools, it has continued to make various tools and instruments to make life easier. When people create or produce new things, they feel joy and come to realize they are alive. When people express their thoughts and feelings via different media, they feel excitement as they concretely express emotion and empathize with others. As Chard [1] argues, the process of project approach goes through a series of stages, like a good story. And project approach to learning focuses on in-depth study of a topic, along with teaching style, learning style and theme[2]. In contrast to a thematic approach, the project approach encourages children to be actively engaged in their own studies, with teachers acting as guides and facilitators. It general consists of three main stages: a start, development, and an end. The project went through these three stages in this study.

Through project work, children in the later phase of early childhood could practice and strengthen their burgeoning skills of counting, measuring, reading, writing, and drawing as these skills are used to represent their ideas, theories, and findings related to the project topic [3]. Kindergarten children often create. Children make creative expressions through language, arts, or body, and express their thoughts through discussion. They also express their thoughts through many other ways, including writing and sculpting. Growing the

Received (November 25, 2017), Review Result (January 12, 2018), Accepted (January 18, 2018) 
strength to communicate their thoughts and emotion and developing and receiving empathy from others through diverse ways are fundamental to demonstrating their thoughts. There are studies such as Photography Project: Project - based Art Activity in Early Childhood [4], The Observation and Effects of Project Approach Method Applied on 'Kimchi Project' Instruction in Elementary Level[5] in the project approach.

Movie-making is one creative activity. Movies allow direct and indirect expression of one's viewpoint and way of thinking. This takes place through the lines of actors, acting, and various items. Creative activity through movie is more efficient than other media, as actions are visually witnessed through screen and can effectively attract the viewer's attention within a short time. Recently, more diverse and efficient movie directing has become possible through CG, and correction. Producing a movie to capture instant moments is a composite art, in which various activities are blended together. Katz, L. G., \& Chard. S. C. [6] and Jeong, Mee-Ae, Son Young-Soo [7] revealed that giving behavioral instructions to children not only improve representational instructions in project activities, but also fosters the desirable dispositions necessary for effective learning, including creativity, problem-solving skills, autonomy, creativity, and curiosity.

Projects provide children with the opportunity for concrete experiences through diverse and rich resources, including associations with the local community and many different organizations. In particular, associations with universities allow children to experience diverse tools. Visiting organizations in the local community where students live also provides them with the opportunity to learn about their roles as members of the community, and how organizations work.

In particular, universities house different departments with various content, and offer specialized education. Therefore, visiting a university gives students a glimpse of specialized knowledge by exposing them to different educational specializations and opportunities. Students can explore their dreams and future careers through associations with universities. Students and professors are also good human resources for teaching and are able to give answers to children's questions. For this reason, this study examined in detail the association with a university and the movie screening process in the movie making project by the children. The set of changes and responses of children were analyzed with the purpose of providing basic data about creative activities for children to inform future research.

\section{Project Background}

Study subjects were 5-year-old children from class 1 at B kindergarten in $\mathrm{K}$ city. The study period was 4 weeks of December 2015. The university associated with this study also serves as the site of the Kindergarten. It is $\mathrm{H}$ university located in $\mathrm{K}$ city. $\mathrm{H}$ university is a specialized institution for broadcasting, and is associated with moviemaking.

Data was collected through the recordings of interactions that took place during and movie making activities. The recordings were then transcribed for analysis. One coteacher, one professor, and one expert reviewed and analyzed the data.

The project process consisted largely of collecting thoughts, exploring movies, finishing the project, and reflecting on the process. In the collecting thoughts stage, a brainstorming session took place so that students could activate their background knowledge about movies. In the exploring movies stage, children had time to share their stories and discuss their experiences of visiting movie theaters. The project was finished through the movie screening, which was developed based on the previous stages. After the movie screening, changes in children's' perceptions and information about movies were examined through the recalling activity.

In order to examine the project process and the changes taking place in children, qualitative analysis, data collection, and expert analysis methods were applied. Data was 
collected through the recording of video clips, photographs, and written records by the author. Qualitative case study focuses more on the process of activities than their results or effects. Thus, the analysis of this study was conducted with a focus on discovering and understanding implications rather than on measuring frequencies or quantity. The following are some examples of data taken found during this process and summaries of some of the findings:

\section{Beginning of the Project: Have You Watched a Movie before?}

\subsection{Have Been to the Cinema}

Children often talked about going to the cinema when they talked about what they did during the past weekend. They recalled their experiences and in detail, including what kind of movie they watched in the cinema, what snacks they had, and where they went.

Minji: Teacher, I went to cinema too!

Teacher: Oh, really? What movie did you watch?

Minji: The... this! (Showing the poster) The main character is this snail here. He was really slow, so everybody was annoyed with him. I ate popcorn, too. I want to eat it again.

(Information was taken from a brainstorming activity on December 7, 2015.)

\section{2. "There Are Posters and Popcorn in Cinema ...."}

After the brainstorming, the children talked about things that are found in cinema, and started to work on role playing. Toys for the role playing were made by the children themselves. They prepared items for movie, chairs necessary for watching a movie, a popcorn machine, and posters in order to decorate the space like a real cinema. The children imitated the movie screening using OHP film.

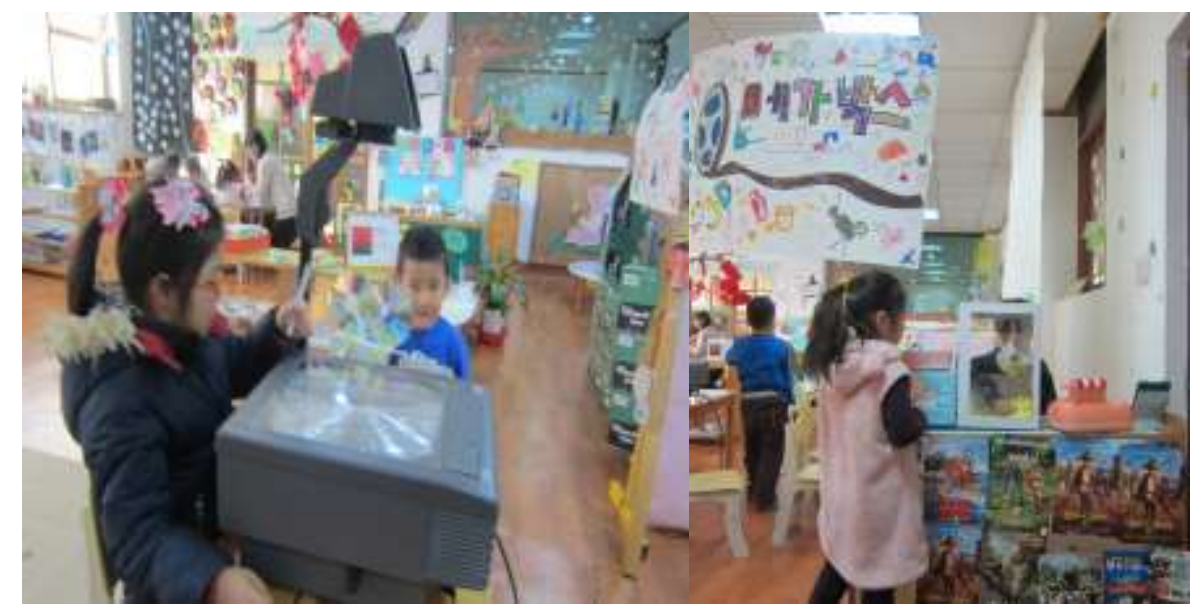

Figure 1. I'Il Show You a Movie! 


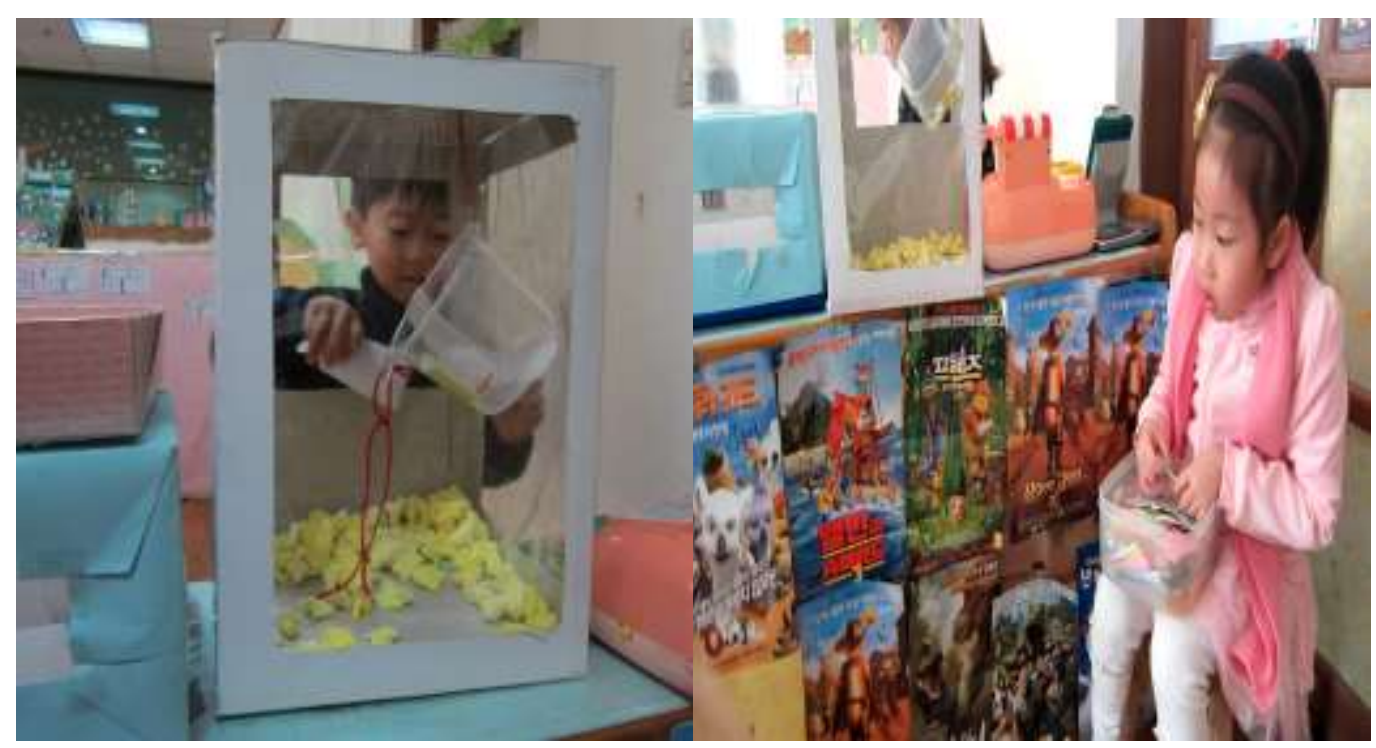

Figure 2. Playing in a Movie Theater

\section{How Is a Movie Made?}

\subsection{It's not like a Movie}

This approach did not meet the expectation of the children; thus, other options were explored. The children grew interested in diverse items and scenarios for a movie through exploration of the movie-making process. They performed various activities, and they filmed a movie based on the scenario they had written on their own.

Jeongbin: But you know, this is not... really like a movie!

Yuri: Do you think so? Then let's do it again.

Jeongbin: Hmm, is this supposed to be a movie?

Teacher: OHP film is not like a movie?

Jeongbin: No.

Teacher: Then what do you think we can do?

(From the free choice activity on December 15, 2015)

\subsection{To Make a Movie!}

The children started to think about ways to make things appear like a real movie. Soon after, they became interested in movie making methods. They learned that many things are required in movie-making, such as scenarios, cameras, and items.

Jeongmi: Teacher, we need a story!

Teacher: That's right. And what else do we need?

Jeongbin: Camera? Oh! Teacher, we have a camera in our class

(holds the camera and looks at it)! Wow, I can see if I do like this! 

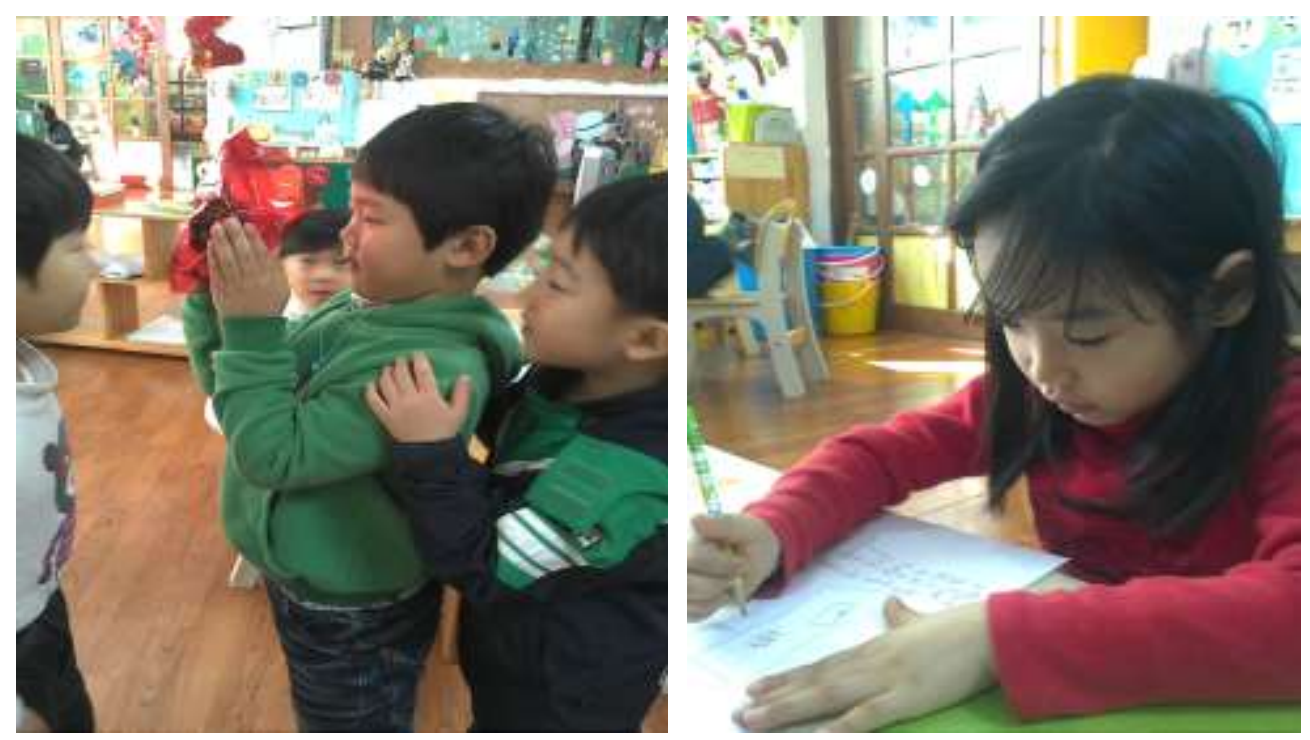

Figure 3. Explore the Camera and Create a Movie Story

\subsection{We Asked Questions to University Students Majoring in Film-Making and Teachers}

The children visited the film department at the university where the kindergarten is located in order to learn about the process of movie-making. After learning about how a movie is made, the children poured out their questions.

University Student 1: Please ask us if you have any questions.

Somi: You know, the cameras are huge!

University Student 1: This camera can film things in close distance and also film things that are far away really clearly. To do this, the lens has to be very large.

Eunha: Then, how do you do to show the film in such darkness in cinema?

University Student 2: you can do it with a device called beam projector. Big cinemas use enormously big projectors.

\section{Our Movie: Iseul's Errand}

\subsection{We Want to Screen Our Movie!}

The children wanted to show the movie they had filmed to their parents and siblings. The teacher explained movie screenings to them, and they decided to screen the movie for their parents and siblings. Those volunteering for the screening event served as ushers for the guests.

Somi: May I ask your seat number?

Parent: It's 4.

Somi: Please take a seat here. This is seat number four.

(On the day of the movie screening on December 29, 2015) 

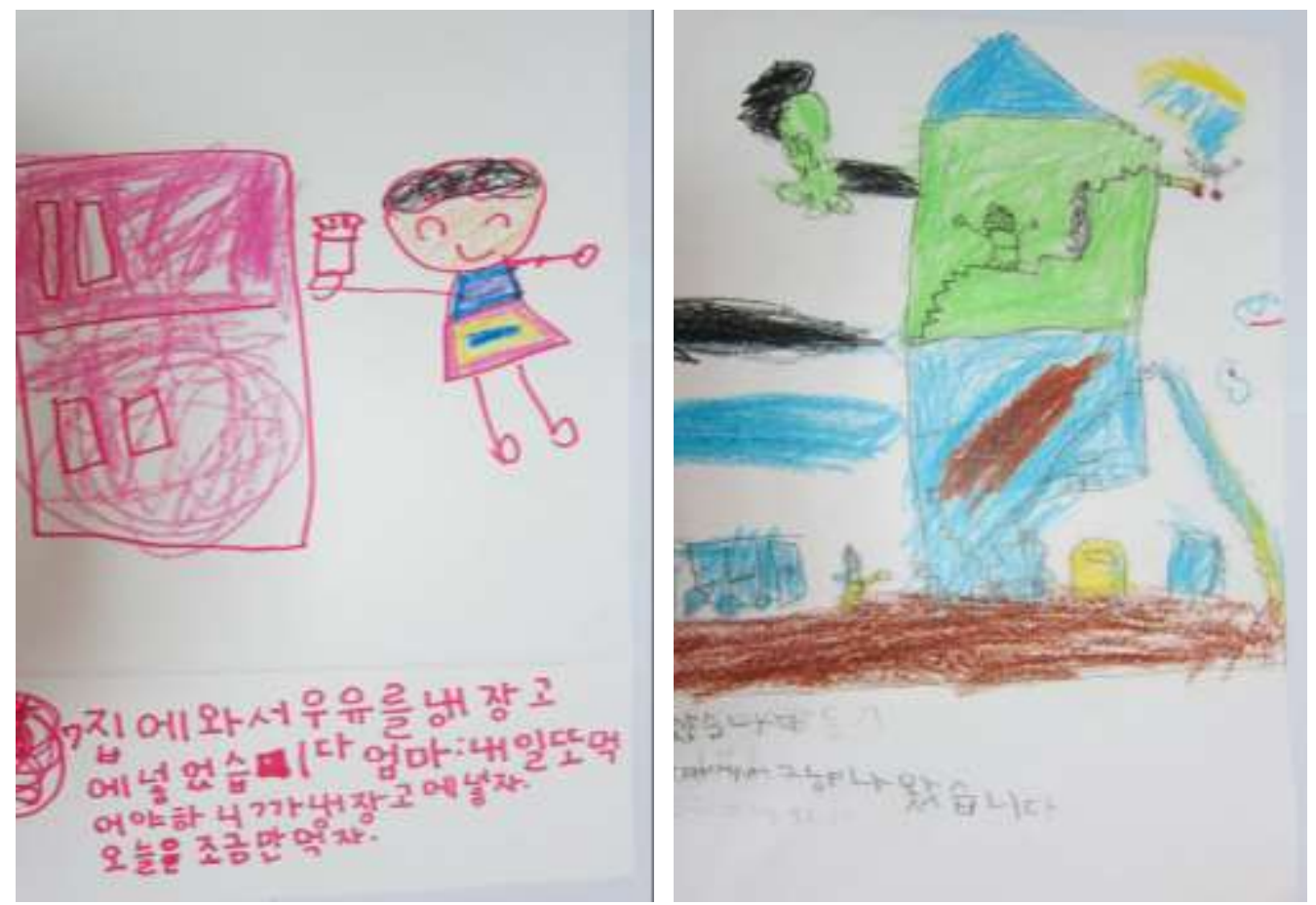

Figure 4. Movie Script

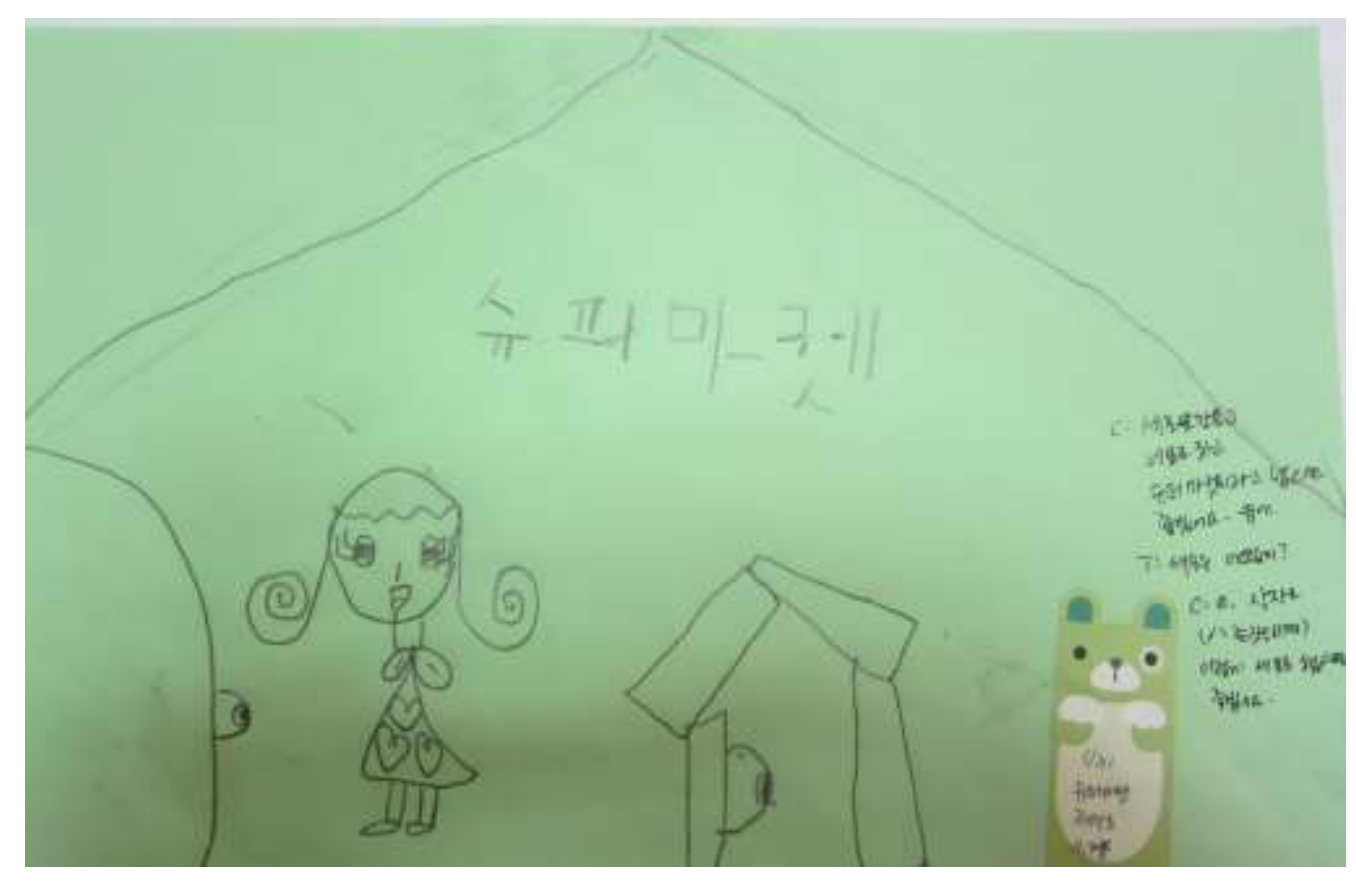

Figure 5. Movie Set Production Plan 


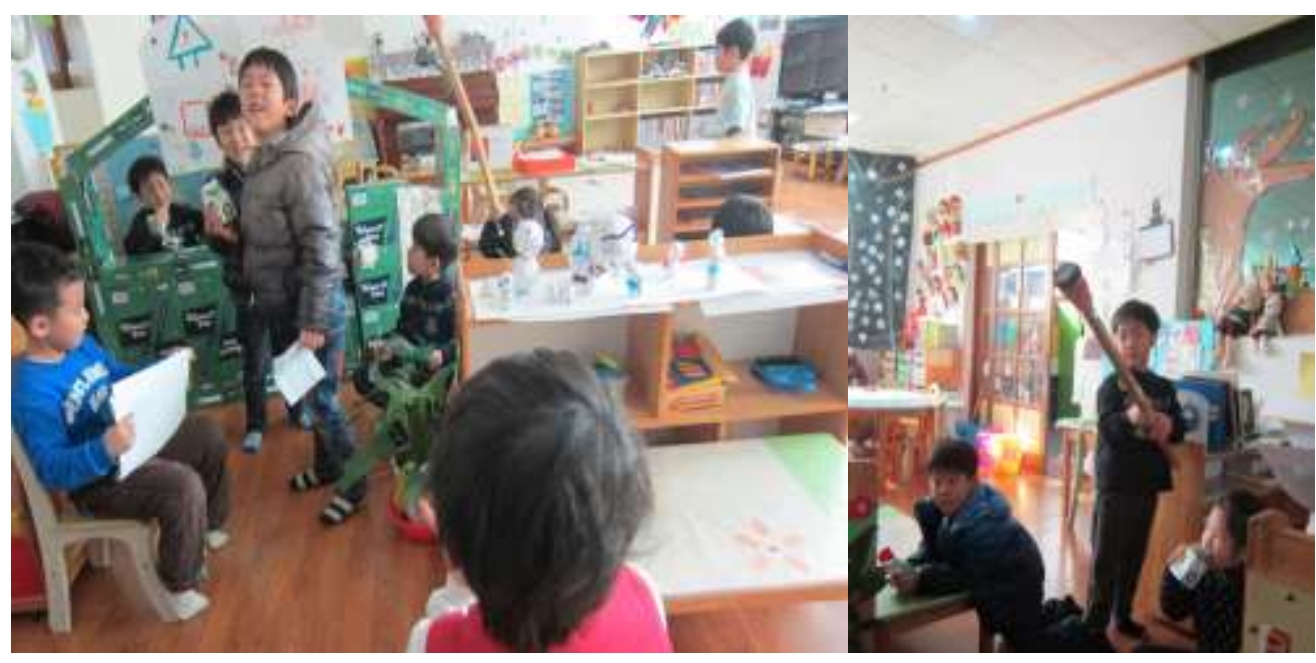

Figure 6. Movie Rehearsal
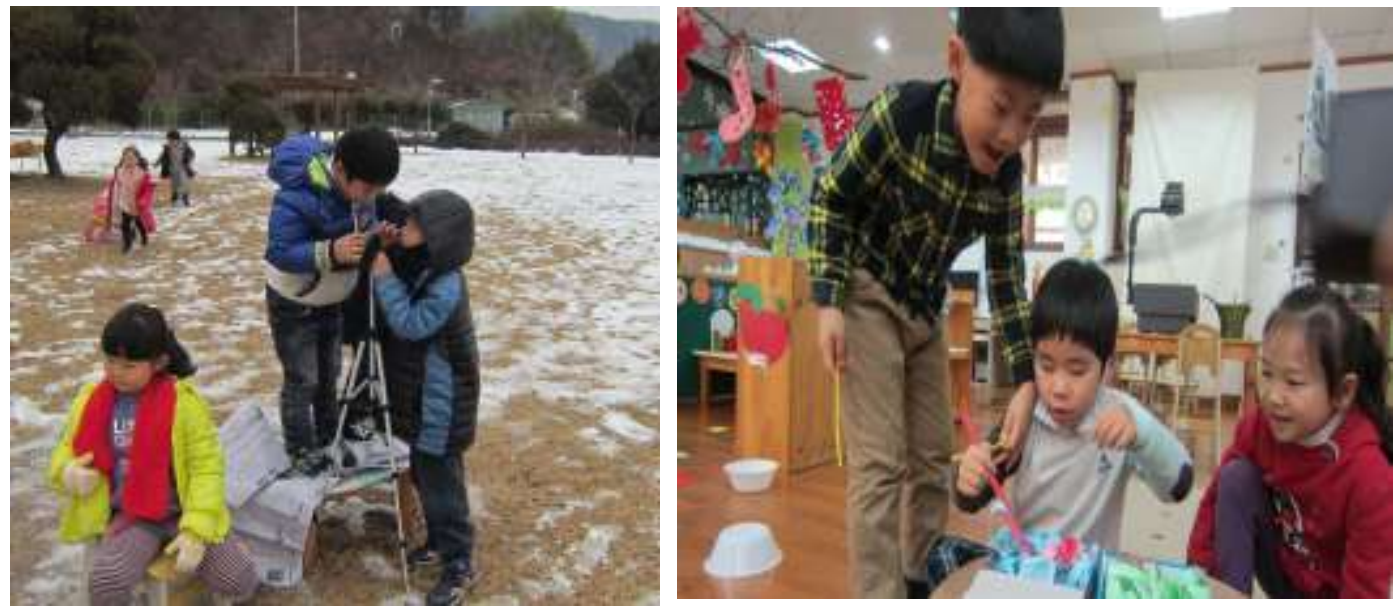

Figure 7. I Shoot a Movie. Ready Action

\section{Concluding the Children's Creative Movie-Making Activity}

The children actively took part in a creative and productive movie making process. In the creative and constructive process of movie-making, the children actively participated and led the movie-making process. In particular, the children showed their diverse ideas about movies through writing scenarios and making items. The movie-making activities were highly meaningful activities for children. And The children actively participated in the activities by presenting their opinions according to the theme and reflecting their opinions in their activities [8].

The children performed various roles in order to screen the movie. They hosted the movie screening out of a desire to share their knowledge with other people. The children quenched their thirst for watching movies with others and connecting with them by screening the movie and then discussing the thoughts and feelings they had experienced during the movie-making process. They learned about the experience from the perspective of the audience. Based on this, it is expected that the children have not only empathized with others but also improved their social skills through this movie project.

An association with community organizations allowed the children to have more diverse experience. Discussion and reflection is an important process in every art project[9]. The improvement in the effectiveness of learning by how the teacher seeks 
local appropriateness of education by selecting projects reflecting children's life and interests is discussed[10]. Diverse experiences through organizations in the local community help children form a solid platform of knowledge necessary for living as local community members. The accumulation of this kind of experiences will serve as a foundation that enables children to perform diverse roles. In particular, the association with the university allowed children to have a more concrete experience. They had a deeply meaningful time as they obtained concrete answers to their questions. The children experienced the actual process of movie-making by using movie-making equipment. Based on this experience, students gained knowledge and information.

To conclude, the children expressed their opinions through diverse ways, and experienced the complex composite art of movie-making. They solved problem on their own in the movie- making process through the activities in this study. A movie project can be considered one of the creative activities.
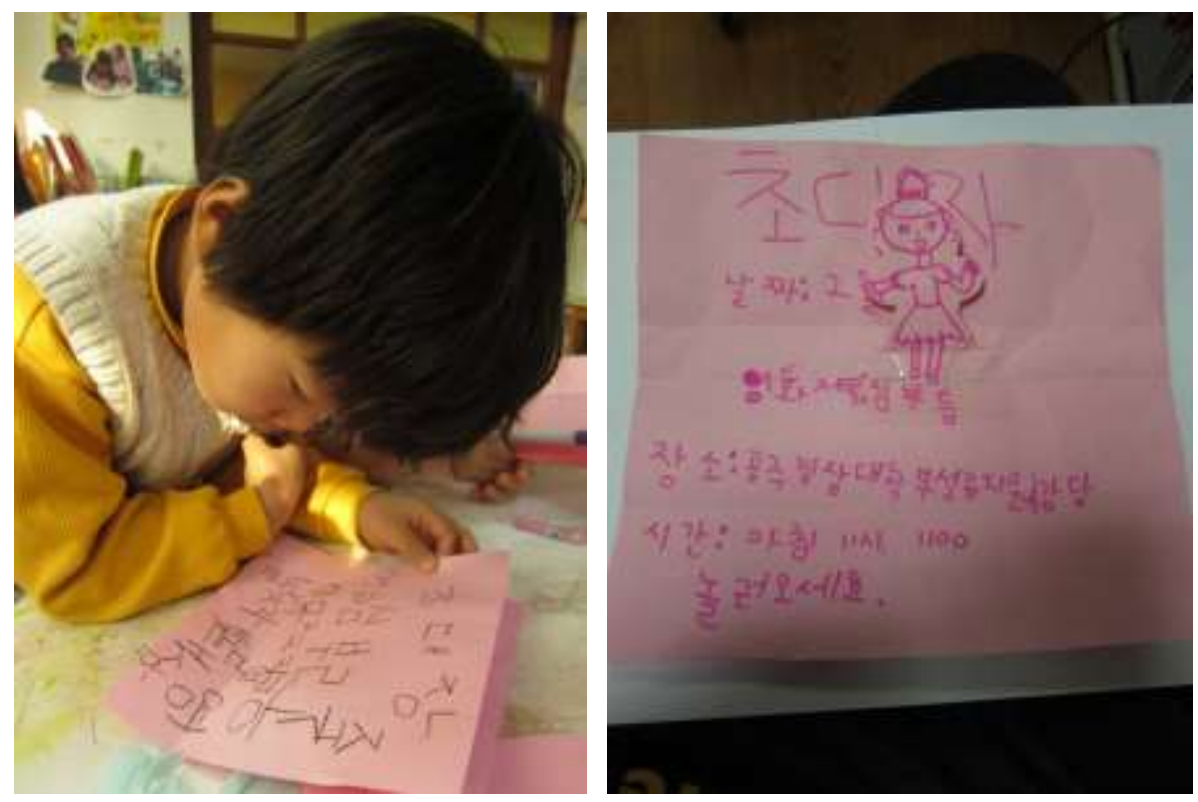

Figure 8. Create an Invitation
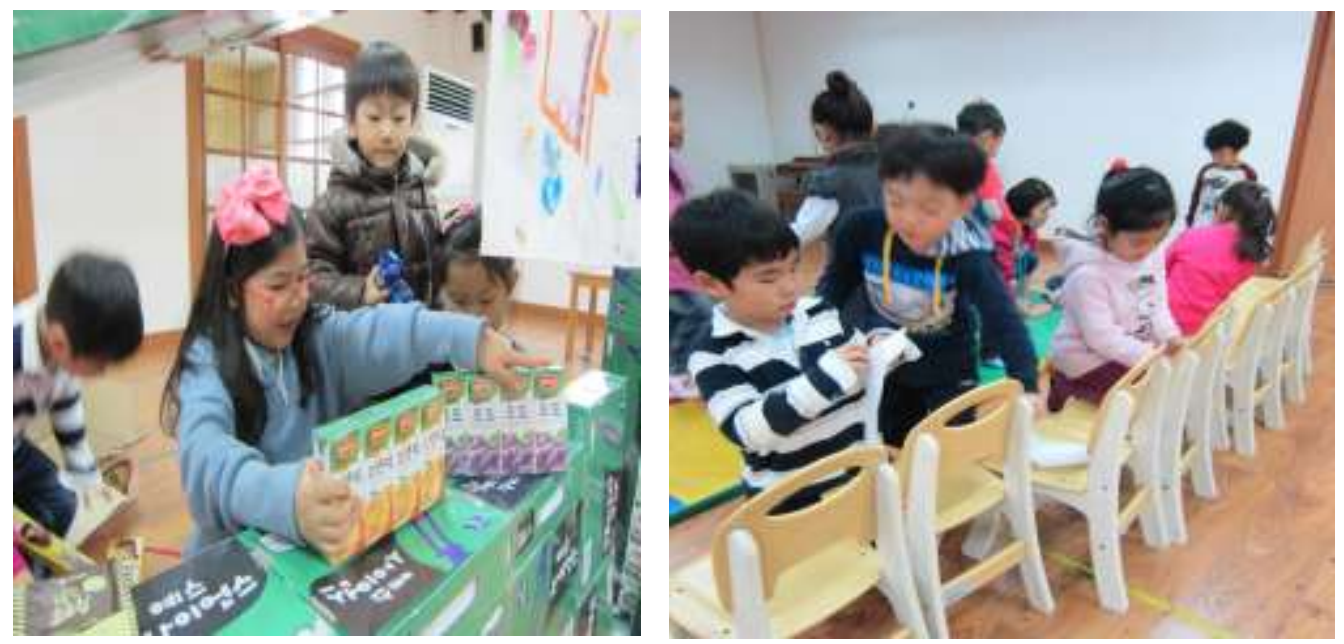

Figure 9. Current Events Decorating 

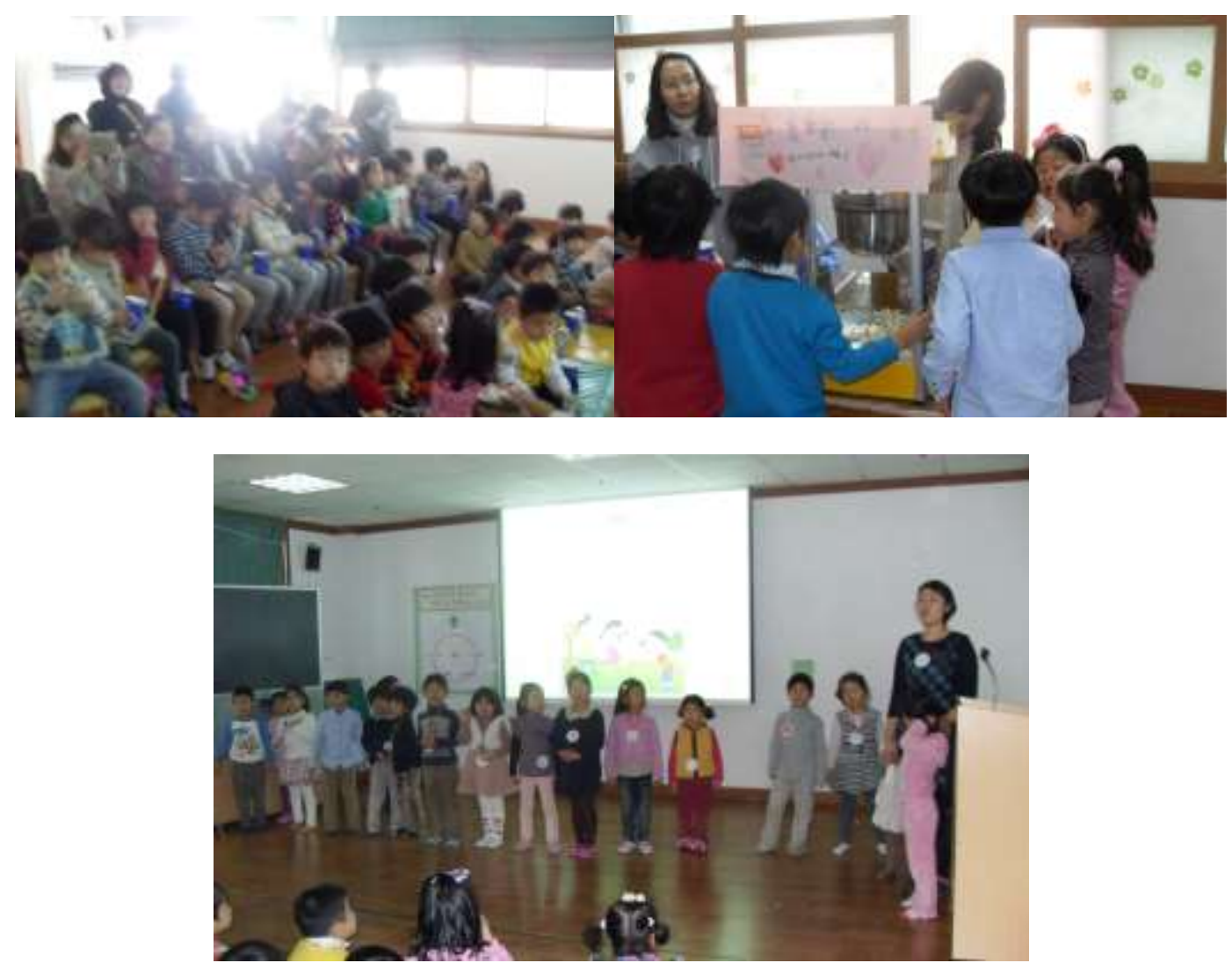

Figure 10. Film Premiere Day

\section{Acknowledgments}

This paper is a revised and expanded version of a paper entitled [Hosting Movie Screening] presented at [International Conferences AST 2017, Hanoi, Vietnam, February 9-12, 2017].

\section{References}

[1] S. C. Chard, "The project approach: A practical Guide for teacher", II . Edmonton Canada university of Albert, Instructional Center, (1994).

[2] B. Cesarone, ERIC/EECE Report: "The Project Approach in Early Childhood Education", Childhood Education, vol. 73, no. 3, (1997), pp. 185-187.

[3] E. Yun, "The Project Approach as a Way of Making Life Meaningful in the Classroom. Proceedings of the Lilian Kazt Symposium", http://ceep.crc.uiuc.edu/pubs/katzsympro.html (Accessed May 12, 2010), (2000).

[4] J. S. Ra, "Photography Project Project - based Art Activity in Early Childhood", Journal of Young Child Studies, vol. 2, no. 1, (1999), pp. 127-145.

[5] G. Ji, O. Yoon and J. Hyun, "The Observation and Effects of Project Approach Method Applied on 'Kimchi Project' Instruction in Elementary Level”, Journal of Korean practical arts education., vol. 21, no. 3, (2008), pp. 7-98.

[6] L. G. Katz and S. C. Chard, "Engaging children's minds", NY: Ablex, (1982).

[7] M.-A. Jeong, Y. -S. Son, "A hermeneutic Research on the Development of Infant's Abilities to Solve Problems through Learning Activities by Project Approach", The Journal of Child Education, vol. 18, no. 4, (2009), pp. 185-200.

[8] K.-C. Kim and E.-O. Kim, "A Study on the Change process of the Infant-Teacher through Project Approach: Focused on the 'Television' Project", Asia-pacific Journal of Education Management Research, vol. 2, no. 1, (2017), pp. 141-146.

[9] K. Reilly, "Art in early childhood: using a project approach", Educating Young Children - Learning and teaching in the early childhood years, vol. 20, no. 3, (2014), pp. 24-27.

[10] 10. Y. Hong, "An inquiry of the Project Approach", Research Institute of Curriculum and Instruction, vol. 1, (1997), pp.186-201. 
[11] K.-C. Kim and E.-O. Kim, "Hosting Movie Screening", Proceedings of the International Conferences AST 2017, Hanoi, Vietnam, (2017).

\section{Authors}

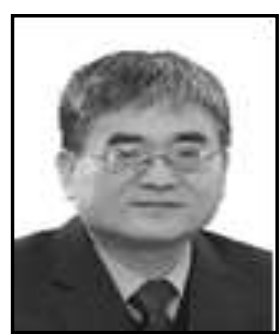

Kyung-Chul, Kim, he is a Professor, Department of Early Childhood Education, Korea National University of Education.

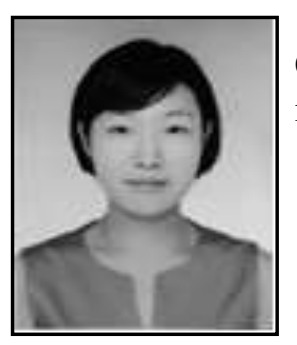

Eun Ok, Kim, she has a Doctor's course, Department of Early Childhood Education, Korea National University of Education. ihope1201@ hanmail.net 